\title{
Prognostic impact of ICG-PDR in patients with hypoxic hepatitis at the intensive care unit
}

\author{
T Horvatits,', N Kneidinger, A Drolz, K Roedl, K Rutter, S Kluge, V Fuhrmann \\ From ESICM LIVES 2015 \\ Berlin, Germany. 3-7 October 2015
}

\section{Introduction}

Hypoxic hepatitis $(\mathrm{HH})$ is a frequent cause of acute hepatocellular damage in critically ill patients associated with high mortality. Indocyanine green, a medical dye, is removed solely by the liver without entering enterohepatic circulation. Therefore its plasma disappearance rate (ICGPDR) is an effective clinical tool for assessment of liver function in acute and chronic hepatic disease.

\section{Objectives}

Aim of this study was to evaluate the prognostic impact of ICG-PDR in comparison to laboratory parameters and established scores in critically ill patients with $\mathrm{HH}$ and other liver disease entities.

\section{Methods}

The impact of ICG-PDR was prospectively evaluated in 119 critically ill patients with different liver disease entities (HH: $n=52$, cirrhosis: $n=35$, acute liver failure (ALF): $\mathrm{n}=10$, control group without signs of acute liver injury, viral or drug induced hepatitis or cirrhosis: $\mathrm{n}=22$ ). Plasma disappearance rate of ICG was measured non-invasively by using a finger pulse densitometry system.

\section{Results}

ICG-PDR on admission was significantly lower in patients with liver diseases (HH, liver cirrhosis, ALF) than in the control group without hepatic impairment (median 5.7\%/min, IQR $3.8-7.9 \% / \mathrm{min}$ vs. $20.7 \% / \mathrm{min}$, IQR $14.1-25.4 \% / \mathrm{min} ; \mathrm{p}<0.001)$.

ICG-PDR predicted 28-day mortality independently of SOFA score and serum lactate in patients with underlying liver disease (HR 1.27, 95\%CI 1.10-1.45; $\mathrm{p}<0.005$ ). AUROC of ICG-PDR predicting 28-day mortality in patients with $\mathrm{HH}$ was significantly higher than AUROC of

University Medical Center Hamburg-Eppendorf, Department of Intensive Care Medicine, Hamburg, Germany
SOFA, arterial serum lactate, INR and AST 48 hours after admission $(\mathrm{p}<0.05)$. ICG-PDR increased significantly in 28-day survivors over course of time ( $p<0.001)$. 28-day survivors could be identified using a cut-off ICG-PDR $\geq$ $9.0 \% / \min 48$ hours after admission with sensitivity of $77 \%$ and specificity $100 \%$.

\section{Conclusion}

Diagnostic test accuracy of ICG-PDR was superior to standard liver function parameters and well established scoring systems in patients with HH. Therefore ICGPDR is a feasible non-invasive tool for early risk stratification in patients with $\mathrm{HH}$.

Published: 1 October 2015

doi:10.1186/2197-425X-3-S1-A974

Cite this article as: Horvatits et al:: Prognostic impact of ICG-PDR in patients with hypoxic hepatitis at the intensive care unit. Intensive Care Medicine Experimental 2015 3(Suppl 1):A974.

\section{SpringerOpen $^{\odot}$}

C 2015 Horvatits et al.; This is an Open Access article distributed under the terms of the Creative Commons Attribution License (http:// creativecommons.org/licenses/by/4.0), which permits unrestricted use, distribution, and reproduction in any medium, provided the original work is properly cited.
Submit your manuscript to a SpringerOpen ${ }^{\circ}$ journal and benefit from:

- Convenient online submission

Rigorous peer review

- Immediate publication on acceptance

- Open access: articles freely available online

- High visibility within the field

- Retaining the copyright to your article

Submit your next manuscript at $>$ springeropen.com 